\title{
The impact of parents' years since migration on children's academic achievement
}

\author{
Helena Skyt Nielsen ${ }^{* *}$ and Beatrice Schindler Rangvid ${ }^{2}$
}

\author{
* Correspondence: \\ hnielsen@econ.au.dk \\ ${ }^{1}$ Department of Economics and \\ Business, Aarhus University, \\ Fuglesangs Allé 4, Aarhus $V$ \\ DK-8210, Denmark \\ Full list of author information is \\ available at the end of the article
}

\begin{abstract}
In this paper, we employ register data for eight cohorts of second-generation immigrant pupils to identify the impact of each parent's years since migration on their children's school achievements. We exploit variation in years since migration and within-family variation. We find evidence of a positive impact of parents' years since migration on children's academic achievement. Mothers' years of residence tend to be more important for Danish, while fathers' years of residence tend to be more important for math. The effects vary by gender, and family-specific effects influence girls' and boys' educational attainment differently.

JEL codes: $121, J 12, J 620$

Keywords: Intergenerational mobility, Years since migration, Scholastic achievement, Immigrant children, Second generation, Fixed effects
\end{abstract}

\section{Introduction}

In Western Europe, there is increasing concern about the assimilation of the children of the large cohorts of guest worker immigrants. Contrary to what one might expect, results from the international PISA, PIRLS and TIMMS studies show that in most Continental European countries immigrants continue to lag significantly behind their native peers even in the second generation (Schnepf 2007; OECD 2010). In the face of a rapidly growing population of second-generation immigrant youth, this is a puzzle of major importance. In this paper, we focus on the effect of parents' years since migration on second-generation pupils' achievement and thus on intergenerational, or inherited, integration. It turns out that the second-generation immigrants, whose parents have spent fewer years since migration in the country of destination before having their child, inherit severe disadvantages from their immigrant parents.

The literature on immigrant outcomes typically focusses on the time (first-generation) immigrants have lived in the host country. For the first generation, time since migration (or age at arrival) reflects both their own and their families' time since migration and thereby their potential integration in the host country. By contrast, second-generation immigrants are typically considered a homogenous group with respect to their potential for integration, since they all - by definition - have been born and raised in the host country. However, they still differ by their families' potential for integration, i.e. their parents' years since migration, and thus by their own potential for intergenerational, or inherited, integration and its derived effect on educational outcomes. Thus,

(C) 2012 Nielsen and Rangvid; licensee Springer. This is an Open Access article distributed under the terms of the Creative Commons Attribution License (http://creativecommons.org/licenses/by/2.0), which permits unrestricted use, distribution, and reproduction in any medium, provided the original work is properly cited. 
in this study, we analyze the effect of parents' time since migration (before the child's birth) on children's educational outcomes at the end of lower secondary education.

We analyze father's and mother's years since migration separately, since parents have not necessarily migrated to Denmark jointly, in which case their time since migration varies. In our sample, $70 \%$ of pupils have parents, who arrived in Denmark more than three years apart in time. One particular source of this variation is the widespread practice among immigrants in Denmark and other European countries of marrying a marriage migrant from their country of origin. ${ }^{[1]}$ This practice may result in substantial differences between father's and mother's years since migration, since one of them may have migrated to Denmark with his/her parents as a child and thus has been raised and educated in Denmark, while the other is a recent immigrant at the time of childbirth.

The literature on effects of immigrants' age at arrival or years since migration is rooted in the theory of transmission of human capital and language capital over generations. Looking first at the parent generation, these studies document that age at migration matters for immigrants' own assimilation as measured by e.g. language proficiency, educational attainment and wages, because there exist certain critical ages in which migration hampers language proficiency and educational progression. ${ }^{[2]}$ As a consequence, the effect of parents' age at migration may be transmitted to the children, and the transmission may work through several different channels.

While there is a small body of literature on the effects of first-generation immigrants' age at arrival on educational outcomes (Böhlmark 2008; Cortes 2006; Gonzalez 2003; Van Ours and Veenman 2006), previous research on the effect of parents' years since migration on their children's education is rare. To our knowledge, this is studied only in one recent paper by (Aslund and Skans 2009). They look at a sample of primarily guest-worker migrants from Nordic countries in Sweden and exploit sibling-fixed effects to identify the effect of the mother's years since migration on e.g. education. They document that a ten-year earlier arrival would increase the length of education by 0.2 years (or $0.1 \mathrm{SD}$ ), which should of course be seen in the light of the relatively advantaged sample of mainly Nordic immigrants that they look at. ${ }^{[3]}$ The authors focus on the effect of the mother's years since migration, and thus they neglect potential effects of diverse migration of the two parents.

Yet, the effect of parents' language proficiency, which is one of the channels through which parents' years since migration may influence their children's education, on children's education and employment has been analyzed. Both (Bleakley and Chin 2008) and (Casey and Dustmann 2008) show that the parents' language skills translate into higher English proficiency of and better educational outcomes for their children. ${ }^{[4]}$ Bleakley and Chin (2008) employ an instrumental variables technique in which the instrument for parents' language skills is the interaction between age at migration and non-English speaking country of origin. Casey and Dustmann (2008) employ a "selection-on-observables" strategy where they exploit rich background information such as parental education and permanent earnings, years since migration, country of origin dummies as well as survey information about parents' contact with residents in the host country. These papers focus on transmission of capital from each of the two parents.

Our goal is to contribute to a better understanding of the sources of the secondgeneration gap by investigating an important potential source: the impact of each parent's years since migration on their children's academic achievement. Parents' years since 
migration is a measure of the potential for integration that encompasses the time the parents had to get accustomed to life in Denmark, learn the language, obtain host country education and labor market experience before they started child rearing. Therefore, it is informative over and above detailed measures of education, employment and language proficiency. Formally, we use ordinary least squares and sibling-fixed effects specifications, we estimate the effect of each parent's years since migration, assuming that variation in parental time since migration/spacing between birth of siblings is random, conditional on observed or unobserved permanent characteristics at the family level.

The present paper contributes to the literature by being the first study to investigate the effect of parental years since migration on children's educational outcomes in a sample that is similar to other current immigrant populations in Continental Europe: refugees and children of guest-worker migrants from non-Western countries. Furthermore, our analysis is novel in its focus on both fathers' and mothers' years since migration, and possible asymmetries in the effects, and in its focus on educational achievement early in the educational career.

In Figure 1, we describe the timing of the set-up in the case in which the father immigrates to Denmark first (e.g. as a guest-worker), and then the (future) spouse follows, and then they have a child. ${ }^{[5]}$ This is the example illustrated in the figure. A similar set-up applies to the cases in which the mother arrives first, or both parents migrate together.

Although the research question is clearly relevant also for other Western countries, the availability of data in Denmark gives us an advantage in this type of investigation, because we can link family members in the Danish registers and follow immigrants from arrival and onwards. Therefore, our empirical analysis is based on Danish register data allowing us to combine information on all pupils in the form 9 cohorts of 20022009 with information about their parents' background characteristics in the year of immigration.

To be specific, we study the impact of each parent's years since migration prior to birth of the child in question on pupils' achievement as measured by subject-specific exam grades in the school exit exams, drop-out and no exam in form 9. We find that generally the mother's years since migration are most important for grades in Danish, while the father's years since migration are most important for grades in math and for drop-out and no exam. This emphasizes the importance of our distinction between each parent's years since migration, which contrasts the approach in the earlier literature. When we split the sample by gender, we find that the positive effect of mother's years since migration only persists for boys. This indicates that family-specific effects influence

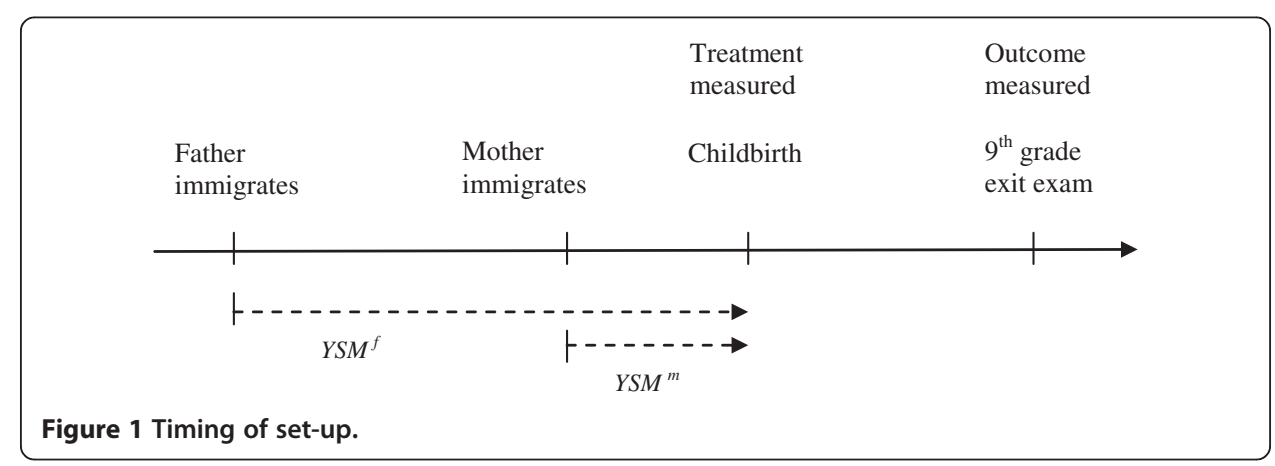


girls and boys differently. A plausible explanation is that family-specific effects include factors that are closely related to norms and attitudes regarding education and gender role patterns, and that this is what shows up in the results.

The remainder of the paper is organized as follows: Section 2 presents the data which are used for the study. Section 3 presents the empirical strategy, while Section 4 contains the results of the empirical analyzes. Section 5 concludes the paper.

\section{Data description}

In this study, we focus on second-generation immigrant children and their parents. Second-generation immigrants are defined as being born in Denmark to two parents, who are both born abroad. In the 2002 cohort of form 9 pupils, 3\% of pupils are second-generation immigrants from non-Western countries, while that number has increased to $6 \%$ in the 2009 cohort.

The reason why we focus on second-generation immigrant children is that they are more comparable to native Danes than children born abroad are, since they have received their entire education in Danish schools and have lived in Denmark all their lives. While it is understandable that the first generation underachieves compared to native Danes (even after accounting for measurable socioeconomic differences), it is much less obvious why this should still be the case in the second generation.

The empirical analysis is based on a data set stemming from administrative registers hosted by Statistics Denmark. The data set contains information on the full population of pupils in the form 9 cohorts graduating in 2002-2009, that is, roughly 480,000 pupils.

The basic estimation data set including only second-generation immigrant pupils from non-Western countries comprises about 20,000 observations. The multichild families data set used for the sibling-fixed effects estimations is smaller, but still sizeable, containing about 12,000 pupils. This data set includes immigrant families with at least two children born in Denmark (i.e. second-generation children) who graduated from form 9 within the 8-year period from 2002-2009.

\subsection{Years since migration}

The variable of main interest in this study is years since migration to Denmark (YSM). It is important to note that unlike other pieces of research in this area we do not consider the time the child has spent in the host country, but the time his or her parents have spent there. The children in our sample are all born in Denmark. We investigate whether the degree of integration of the child's parents (approximated by the time the parents have lived in Denmark) spills over into children's educational attainment.

The time the father and mother have spent in Denmark, prior to birth of the child in question, is a measure of the time the parents had to get accustomed to life in Denmark, learn the language, obtain host country education and labor market experience before the child was born, and, thus, before they started child rearing.

Figure 2 shows the distribution of time since migration for fathers and mothers at the time the child is born. For parents arriving before 1973, we do not know the exact year of arrival, although we know that they were not born in Denmark. The black parts of the columns summarize years since migration when the exact year of arrival is known, while the grey parts indicate that exact years since migration are missing. ${ }^{[6]}$ 


\section{Father}

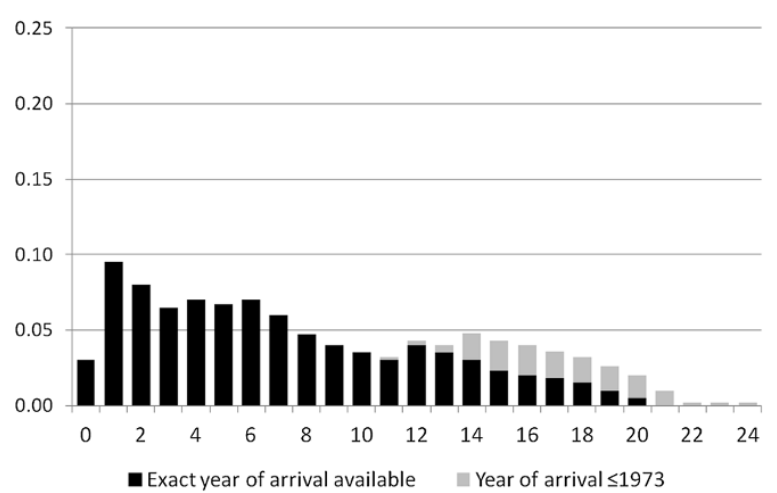

Mother

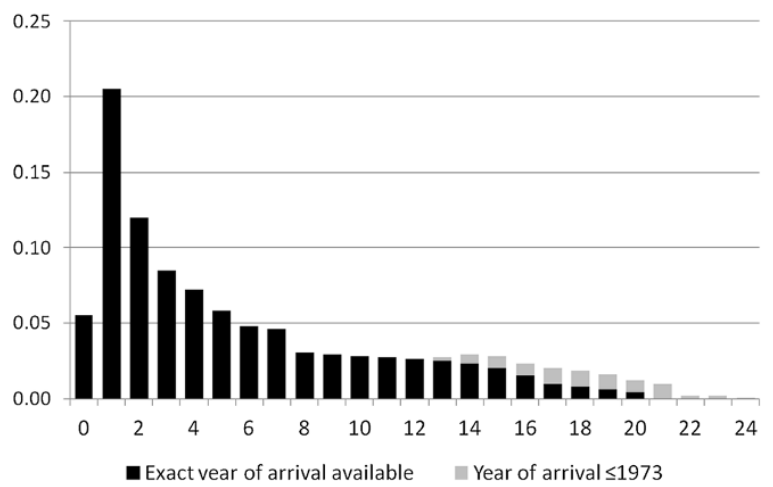

Figure 2 Histograms of fathers' and mothers' years since migration before childbirth.

Many parents were recent arrivers in Denmark at the time of birth of their children, while only few parents have enjoyed a long residence in Denmark or have grown up in Denmark. There are substantially more mothers than fathers who came to Denmark within five years before childbirth (10,000 compared to 7,000).

Figure 3 shows how parents on average have spent the period between their immigration to Denmark and having the child. We distinguish between (accumulated) years spent in employment, in education, and time spent temporarily (e.g. due to unemployment) or permanently (e.g. social transfer income) away from the labor
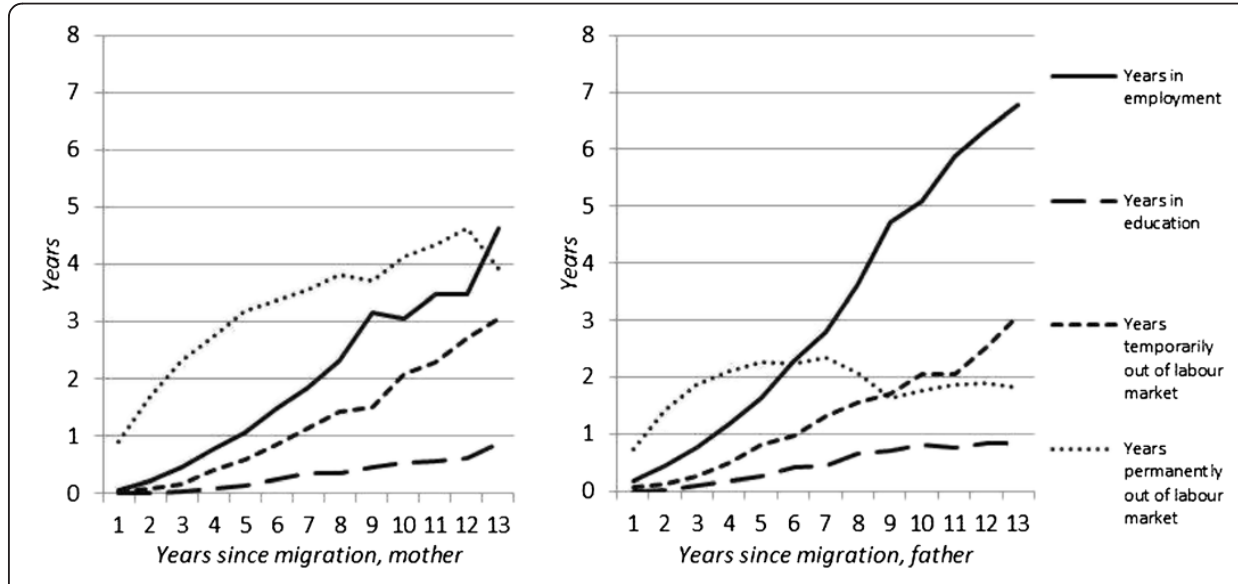

Figure 3 How parents spent the time between immigration and childbirth. 
market and education. ${ }^{[7]}$ We posit that both time spent in employment and in education improves parents' (Danish) language skills and their knowledge about life in Denmark, while time spent away from the labor market or education (i.e. time spent at home) does not encourage integration to the same degree. Figure 3 indicates that parents have spent very little time in education. Employment is the dominant activity for males, who have spent more than six years in Denmark at the time of childbirth, while permanent non-labor-market activities are the dominant activities among females. For both males and females, the amount of and the proportion of time spent in the labor market and in education are higher when they have spent a longer period of time in Denmark before childbirth. Supposedly, this promotes their language skills and knowledge of life in Denmark, which we posit should help increase their children's outcomes.

For the purpose of the empirical estimation, we design categories for years since migration so that the uppermost category includes all individuals arriving prior to 1973, where the exact year of arrival is unknown. We classify YSM into four categories: 0-4, $5-9,10-13$, and 14 or more years since migration. ${ }^{[8]}$ Figure 3 documents that mothers and fathers in the lowest category have very limited labor market experience and education (around 25\% of time spent in Denmark), while parents in the highest category in particular fathers -have substantial labor market experience and education (around $50 \%$ of time spent in Denmark).

We consider both the father's and the mother's years since migration, because only some of them arrived in Denmark as a couple. Part of the older immigrant population in Denmark has come to Denmark as children together with their parents. Since marriage migration of spouses is frequent, one parent would often have been raised in Denmark, while the other comes to Denmark as an adult to marry the Danish resident.

In Table 1, we show the joint distribution across the categories of years since migration of the parents. The table shows that $54 \%$ of pupils have been born to recently arrived mothers and 34\% to recently arrived fathers (YSM: 0-4 years). A total of 951 pupils (5\%) are born to parents who both grew up in Denmark (YSM: 14 years or more). In our sample, about one third of pupils grow up in a family where the parents arrived at roughly the same time and are most likely tied movers (the diagonal), while

Table 1 Distribution of the sample by years since migration of each parent

\begin{tabular}{lccccc}
\hline & \multicolumn{5}{c}{ YSM father } \\
\cline { 2 - 6 } YSM mother & $\mathbf{0 - 4}$ years & $\mathbf{5 - 9}$ years & $\mathbf{1 0 - 1 3}$ years & $\mathbf{1 4 +}$ years & All \\
\hline 0-4 years & 0.205 & 0.158 & 0.061 & 0.113 & 0.538 \\
& 4,337 & 3,343 & 1,295 & 2,397 & 11,372 \\
5-9 years & 0.043 & 0.062 & 0.036 & 0.068 & 0.210 \\
& 918 & 1,317 & 763 & 1,438 & 4,436 \\
10-13 years & 0.032 & 0.018 & 0.013 & 0.042 & 0.104 \\
& 681 & 383 & 265 & 877 & 2,206 \\
14+ years & 0.056 & 0.034 & 0.014 & 0.045 & 0.148 \\
& 1,193 & 711 & 285 & 951 & 3,140 \\
All & 0.337 & 0.272 & 0.123 & 0.268 & 1.000 \\
& 7,129 & 5,754 & 2,608 & 5,663 & 21,154 \\
\hline
\end{tabular}


the remaining two thirds grow up in a family where one parent arrived in Denmark considerably earlier than the other.

\subsection{Outcome variables}

The main outcomes considered are exam grades from the national school exit exams at the end of form 9. We use grades for written Danish and math. As an additional outcome variable, we measure whether pupils take the exam or not. Below, we describe these outcome measures in more detail.

\section{Grades}

As a measure of pupils' academic achievement, we use grades from the (written) national school exit exams in form 9. The results from the school exit exams are normally considered comparable across schools. The written exams are identical across schools and are graded by the teacher and an external examiner whose opinion dominates the teacher's opinion.

We use only grades from written exams. ${ }^{[9]}$ We create an outcome for Danish grades in which the one-dimensional composite measure for Danish is calculated as the simple mean of the pupils' grades for written Danish and spelling. As outcome for Math achievement, we use grades from the written Math exam(s). ${ }^{[10]}$

Before 2008, a 13-point numerical grading scale system was used. ${ }^{[11]}$ From 2008 onwards, an internationally comparable seven-point scale was introduced. ${ }^{[12]}$ To be able to compare grades across cohorts, we standardize grades to zero mean and unit standard deviation within each cohort.

Figure 4 shows average grades for second-generation pupils and natives for Danish and math. The exam results for the average second-generation pupil are lower than for the average native, and it is stable across cohorts (e.g. no closing or widening of the gap between the second generation and natives) over the period. The disadvantage of the second generation is more prevalent for math than for Danish.

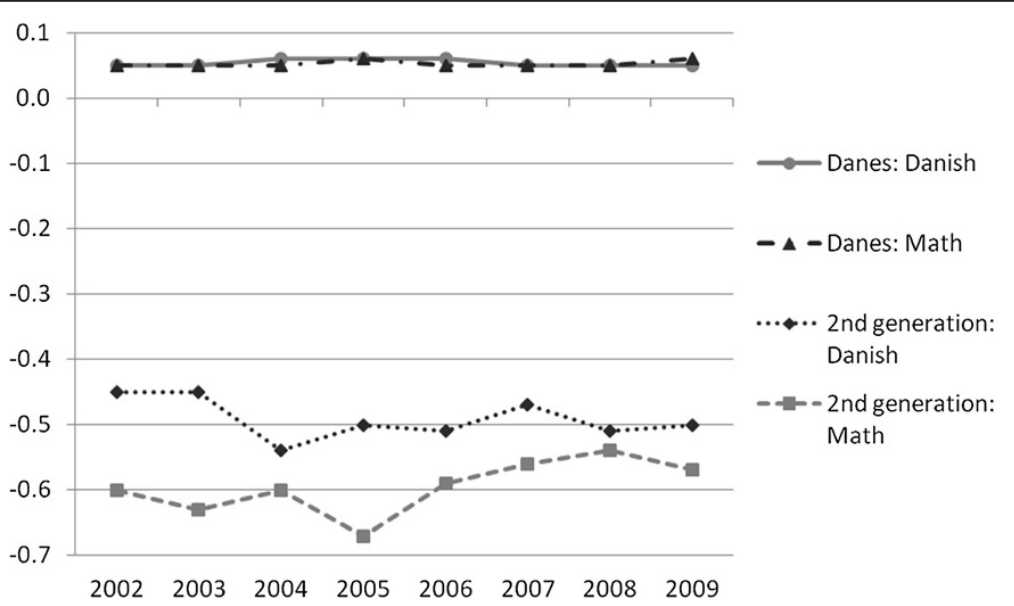

Figure 4 Average standardized grades in Danish and math for second-generation pupils and natives. 


\section{Taking the exam or not}

Until 2007, taking the school exit exam has not been compulsory. As shown in Figure 5 (right hand side), the percentage of second-generation pupils not taking the exam has been about 5\%, while the corresponding number for natives has been around $2.5 \%$. After making the exam compulsory in 2007, there was a sharp drop in the rate for second-generation pupils not taking the exam to around $3 \%,{ }^{[13]}$ while the already low rate for Danes drops only slightly from $2.5 \%$ to $2 \%{ }^{[14]}$ When also counting individuals who drop out of school during form 9 (see Figure 5, left hand side), and who for that reason are not observed to take the exam, the $3 \%$ non-attendance for secondgeneration pupils increases to $9 \%$. A comparison of the left hand side and right hand side of the figure indicates that the decline in no exam was followed by an increase in drop-out. This indicates that some second-generation immigrant pupils decided to drop out instead of quitting the exam, when that was banned.

In the regressions, we define an outcome variable which equals one if the pupil has not taken at least one exam for a sub-domain of Danish and a sub-domain of math, and which equals zero otherwise. We analyze this outcome both for the sample of individuals present in form 9 at the time of the exit exam, and for the sample of individuals who entered form 9 after the summer break.

\subsection{Control variables}

At the pupil level, we control for gender, birth order, country of origin, parents' ages at arrival, parents' education and the presence of older siblings born in the country of origin. Table 2 shows descriptive statistics for the control variables used in the regressions, both for the full sample and for the multi-child sample used for the sibling-fixed effects regressions.

Of the second-generation pupils in our full sample, about $36 \%$ have origins in Turkey, about $13 \%$ in Lebanon, about $10 \%$ in Pakistan and other 5\% in former Yugoslavia. The average age at arrival is 21 and 23 years for mothers and fathers, respectively, and although information about education before arrival in Denmark is most often missing, it is striking that only $2.5 \%$ of the mothers and $3.5 \%$ of the fathers are observed to have acquired education beyond high school before arrival in Denmark. The percentage of pupils who have (older) siblings born before arrival in Denmark is 22\%, and the percentage of firstborn pupils in the sample is 39\%.

Summary statistics in the multi-child sample are similar to those in the full sample except for variables that are directly related to the selection into the sample, e.g. the

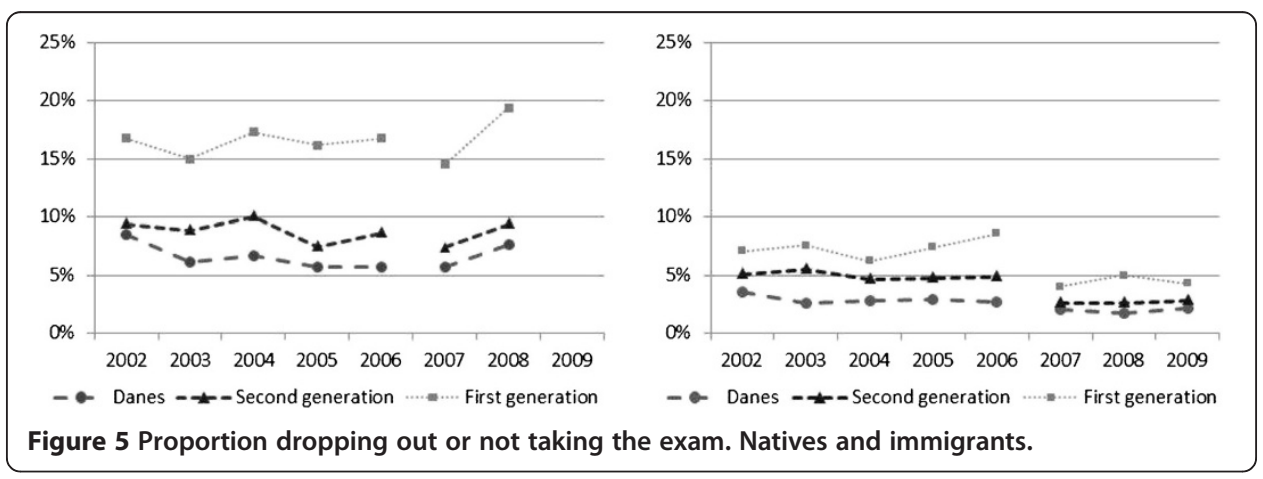


Table 2 Descriptive statistics

\begin{tabular}{|c|c|c|c|c|}
\hline & \multicolumn{2}{|c|}{ Full sample } & \multicolumn{2}{|c|}{ Multi-child sample } \\
\hline & Mother & Father & Mother & Father \\
\hline Years since migration & 5.7 & 7.7 & 5.8 & 5.7 \\
\hline \multicolumn{5}{|l|}{ Parents' education from country of origin } \\
\hline Lower secondary school (max.) & 0.13 & 0.09 & 0.13 & 0.10 \\
\hline Vocational education & 0.04 & 0.06 & 0.03 & 0.05 \\
\hline High school & 0.03 & 0.02 & 0.03 & 0.02 \\
\hline Short cycle higher education & 0.01 & 0.01 & 0.01 & 0.01 \\
\hline Medium cycle higher education & 0.01 & 0.01 & 0.01 & 0.01 \\
\hline Long cycle higher education & 0.01 & 0.01 & 0.00 & 0.01 \\
\hline Missing education & 0.78 & 0.79 & 0.78 & 0.80 \\
\hline \multicolumn{5}{|l|}{ Parents' age at arrival } \\
\hline Age at arrival (if not missing) & 21.1 & 22.6 & 20.1 & 21.6 \\
\hline (SD Age at arrival) & 6.3 & 7.4 & 5.9 & 6.9 \\
\hline Missing age at arrival & 0.09 & 0.22 & 0.09 & 0.19 \\
\hline Presence of (older) siblings born in country of origin & \multicolumn{2}{|c|}{0.22} & \multicolumn{2}{|c|}{0.16} \\
\hline Firstborn child & \multicolumn{2}{|c|}{0.39} & \multicolumn{2}{|c|}{0.31} \\
\hline Male & \multicolumn{2}{|c|}{0.50} & \multicolumn{2}{|c|}{0.49} \\
\hline \multicolumn{5}{|l|}{ Country of origin } \\
\hline Turkey & \multicolumn{2}{|c|}{0.36} & \multicolumn{2}{|c|}{0.39} \\
\hline Lebanon & \multicolumn{2}{|c|}{0.13} & \multicolumn{2}{|c|}{0.15} \\
\hline Pakistan & \multicolumn{2}{|c|}{0.10} & \multicolumn{2}{|c|}{0.13} \\
\hline Ex-Yugoslavia & \multicolumn{2}{|c|}{0.05} & \multicolumn{2}{|c|}{0.05} \\
\hline \multicolumn{5}{|l|}{ Outcome measures } \\
\hline Grade in Danish exam & \multicolumn{2}{|c|}{-0.49} & \multicolumn{2}{|c|}{-0.55} \\
\hline Grade in Math exam & \multicolumn{2}{|c|}{-0.59} & \multicolumn{2}{|c|}{-0.63} \\
\hline Drop-out/no exam & \multicolumn{2}{|c|}{0.09} & \multicolumn{2}{|c|}{0.08} \\
\hline No exam & \multicolumn{2}{|c|}{0.04} & \multicolumn{2}{|c|}{0.04} \\
\hline Number of observations & \multicolumn{2}{|c|}{21,154} & \multicolumn{2}{|c|}{12,393} \\
\hline
\end{tabular}

share of firstborns is smaller in the multi-child sample since this sample does not include only children.

In our sample of second-generation pupils, the relationship between YSM and children's exam grades is strong. ${ }^{15}$ The graphs in Figure 6 display means for the standardized grades in Danish and Math exams for each value of YSM. The means are regression-adjusted for gender, birth order, country of origin, parents' ages at arrival, parents' education and the presence of older siblings born in the country of origin. Consistent with our expectations, children of mothers, who were recent arrivers at the time of the child's birth, do worse in the exam than children of long-term resident mothers.

\section{Empirical strategy}

We investigate the impact of each parent's years since migration (YSM) prior to birth of the child on the child's Outcome. Our identification strategy comprises two steps. 

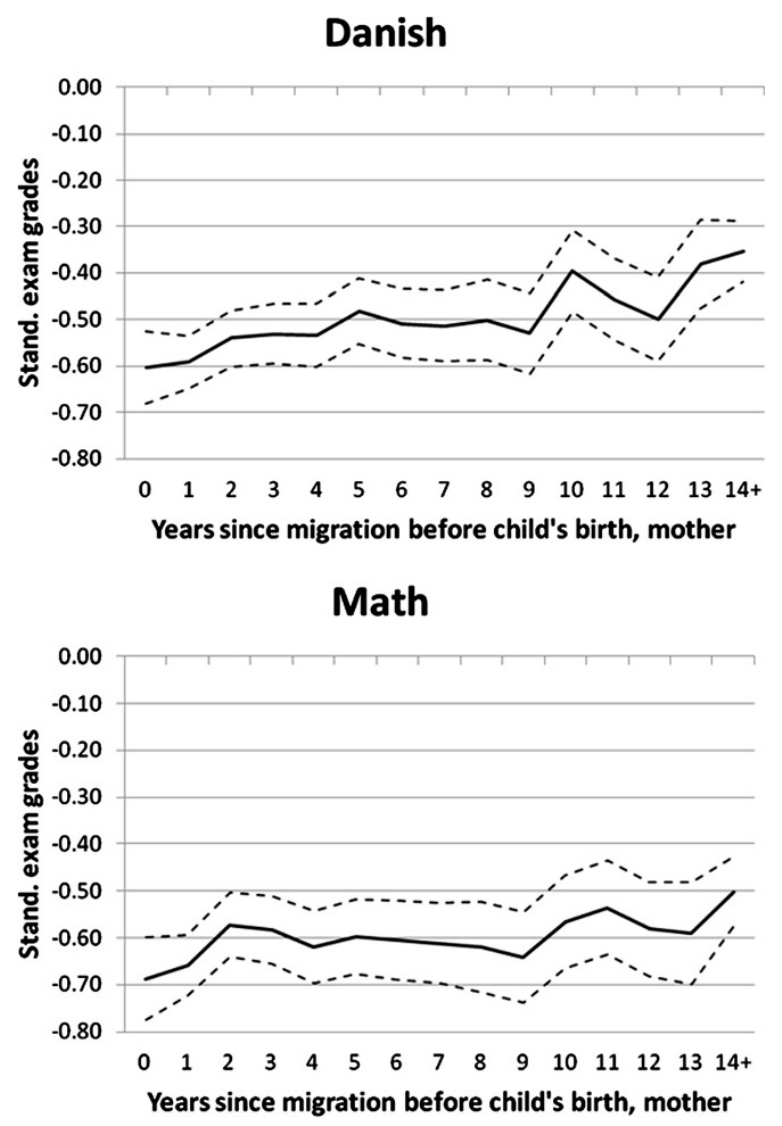

Figure 6 Regression-adjusted means.

First, we use basic OLS estimations as our baseline results, including predetermined control variables in our regressions of YSM on outcomes and thereby reducing biases that are thought to influence both YSM and outcomes. Thus, conditional on observables, it is assumed to be random how many years the parents have spent in the country before they have a child. Yet, since YSM may still be related to unobserved parental characteristics that also influence pupil outcomes, we estimate sibling-fixed effects models to control for time-invariant observed and unobserved characteristics at the family level, such as taste for education, ability, norms. The key advantage of using differentials in parental years since migration for siblings is that it offers a natural way of eliminating the family-specific heterogeneity biases associated with migration and birth timing choices. In our context, the primary assumption in this model is that a couple's birth spacing decisions are independent of those characteristics of the individual children in the family that are also related to educational outcomes. ${ }^{[16]}$ As a result, the omitted parental characteristics as, for example, concern for or time spent with the children can be captured in a family-specific error term. Estimating sibling-fixed effects models and comparing them to the OLS results, we examine whether unobserved characteristics that are shared by all siblings in a family do indeed drive our OLS findings that years since migration matter for children's educational outcomes.

However, sibling-based fixed effects models are no panacea because they leave open the possibility of omitted variable bias due to unobserved within-family heterogeneity. 
Moreover, it is only children with second-generation siblings graduating within the 2002-2009 period who contribute to identification of the coefficients when the siblings approach is used, and this raises some concerns about how general the results are.

\subsection{Baseline: Basic OLS}

For the baseline empirical specifications, we estimate variations of the following model using OLS regressions:

$$
\text { Outcome }_{i f}=\beta Y S M_{i f}+\delta \text { Pupil }_{i f}+\text { OFamily }_{f}+\varepsilon_{f}+\varepsilon_{i f}
$$

The outcomes, e.g. exam grade, are a function of pupil-specific variables, Pupil $l_{i f}$, family-specific variables, Family $f_{f}$, and parental years since migration, $Y S M_{i f}$. The error term has two components: a family-specific error term $\varepsilon_{f}$ that includes omitted characteristics that are constant for siblings, and a random error term $\varepsilon_{i f}$. The crucial assumption for OLS to identify the effect of YSM is that the covariates sufficiently proxy variables influencing both YSM and the outcome, such that, for instance, $\varepsilon_{\mathrm{f}}=0$ over the entire distribution of YSM. Thus, conditional on observables, it is assumed to be random how many years the parents have spent in the country before they have a child. This is clearly a strong assumption. Therefore, we proceed by estimating sibling-fixed effects, which need much weaker assumptions for identification.

\subsection{Sibling-fixed effects}

Even though we control for many predetermined parental characteristics that might influence both parental years since migration and children's outcomes (e.g. country of origin, parental education), the estimate of $\beta$ might still be biased due to the correlation between YSM and unobserved family characteristics $\left(\varepsilon_{\mathrm{f}}\right)$ Thus, we pursue an alternative approach that exploits the observation that the latent family factors associated with parents' migration and birth timing choices are sibling-invariant.

The sibling approach can be motivated by the presence of self-selection in the migration and birth timing decisions. Concerning our variable of interest (years since migration of parents), two choices are involved: the choice of when to migrate and when to have a child. For parents who came to Denmark as childhood migrants, the choice of when to migrate was that of their parents (i.e. the grandparents of our secondgeneration pupils). However, as laid out in Böhlmark (2008), if their parents' choice of when to migrate (i.e. while the children are still young or later [17] ) is related to their taste for education, etc., and if that again is transmitted through generations, parental age at arrival is not exogenous to the present generation's educational outcomes. Moreover, and likely more important, if the decision on when to have a child (after migration) is related to unobserved parental characteristics which also influence children's educational outcomes, basic OLS estimates are likely to be (upward) biased. Parents who have the insight and the possibility of considering accumulating host countryspecific skills before having children are likely to be overrepresented among those who accumulate more "years since migration" before childbirth. These parents are also more likely to possess characteristics that are good for their children's educational outcomes. The fact that the parents consider the length of time between migration and childbearing (=timing of migration and child bearing) will induce selection bias. 
Yet, applying the siblings strategy will net out any omitted variables capturing timeinvariant/persistent, family-specific characteristics. ${ }^{[18]}$ This approach is well suited since the explanatory variable of interest shows much within-family variation at the same time as many of the confounding factors, both observed (like e.g. country of origin) and unobserved (like parental ability), are permanent family characteristics.The fixed effects model can formally be written as:

$$
\text { Outcome }_{i f}=\beta Y S M_{i f}+\delta \text { Pupil }_{i f}+\mu_{f}+\varepsilon_{i f}
$$

In this specification, Pupils $s_{i f}$ includes gender and birth order controls, ${ }^{[19]}$ while controls at the parents' level are omitted, since they are common among siblings and are included in the family-fixed effects term $\mu_{f}$ which captures both observed and unobserved family characteristics.

Since parents of younger siblings have spent more years in Denmark before having the child than they had when their older children were born, this introduces variation in parents' YSM for siblings. This reflects the fact that the parents have had more time to integrate when raising their later born children. Thus, identification of $\beta$ relies upon the sibling variation in parental years since migration at the child's birth (i.e. birth timing after migration). The coefficient vector would then not be subject to any bias due to the influence from unobservables captured in the fixed effects that are also associated with educational outcomes. Hereby we can handle the impact of unobserved family characteristics which may be correlated with parents' years since migration.

To sum up, the identifying assumption for our baseline OLS specification is that, conditional on observables, it is random how many years the parent spends in the country before having a child. The identifying assumption for our sibling-fixed effects model is that the most important omitted parental influences are time-invariant familyspecific characteristics that are netted out by a sibling-fixed effect. There is no reason to believe that the estimates from these two models should give identical or directly comparable results, because the sibling-fixed effects model exploits within-family variation, whereas the baseline OLS captures the total within- and between-family variation.

\section{Results}

In this section, we present the results from estimations of the impact of parents' years since migration on educational outcomes in form 9. In the first subsection, we present the main results showing the effect on grades in Danish. In the second subsection, we investigate the effect of years since migration on three further outcomes: math grades, drop-out and whether the pupil takes the exam or not. Then we investigate heterogeneity by focusing on particular subgroups, and, finally, we perform a range of robustness checks.

\subsection{The effect of years since migration on grades in Danish}

\subsubsection{Baseline: Basic OLS}

Before turning to the main results, we first ascertain that the conditioning set actually explains some of the variation in grades and years since migration. Therefore, in Table 3, we present the full set of regression results including estimated parameters for the set of two times four indicator variables measuring the father's and mother's years since migration as well as the conditioning variables. ${ }^{[20]}$ 
Table 3 Full set of results for exam grades in Danish (Basic OLS)

\begin{tabular}{|c|c|c|c|c|c|c|c|c|c|c|c|}
\hline & & \multicolumn{2}{|c|}{$(1)$} & \multicolumn{2}{|c|}{$(2)$} & \multicolumn{2}{|c|}{ (3) } & \multicolumn{2}{|c|}{ (4) } & \multicolumn{2}{|c|}{ (5) } \\
\hline \multirow[t]{4}{*}{ Mother: years since migration } & $0-4$ & \multicolumn{10}{|c|}{ (Reference) } \\
\hline & $5-9$ & -0.012 & $(0.017)$ & -0.011 & $(0.017)$ & -0.009 & $(0.017)$ & -0.002 & $(0.017)$ & $0.035(*)$ & $(0.018)$ \\
\hline & $10-13$ & 0.032 & $(0.022)$ & $0.042(*)$ & $(0.024)$ & $0.046(*)$ & $(0.024)$ & $0.056^{*}$ & $(0.024)$ & $0.101^{* * *}$ & $(0.025)$ \\
\hline & $14+$ & $0.089^{* * *}$ & $(0.019)$ & $0.133^{* * *}$ & $(0.029)$ & $0.129^{* * *}$ & $(0.029)$ & $0.148^{* * *}$ & $(0.029)$ & $0.192^{* * *}$ & $(0.029)$ \\
\hline \multirow[t]{4}{*}{ Father: years since migration } & $0-4$ & \multicolumn{10}{|c|}{ (Reference) } \\
\hline & $5-9$ & 0.024 & $(0.017)$ & $0.037^{*}$ & $(0.017)$ & $0.038^{*}$ & $(0.017)$ & 0.020 & $(0.017)$ & $0.041^{*}$ & $(0.017)$ \\
\hline & $10-13$ & -0.019 & $(0.022)$ & 0.011 & $(0.025)$ & 0.014 & $(0.024)$ & 0.007 & $(0.024)$ & $0.043(*)$ & $(0.025)$ \\
\hline & $14+$ & 0.010 & $(0.018)$ & $0.092^{* * *}$ & $(0.026)$ & $0.085^{* * *}$ & $(0.025)$ & $0.080^{* *}$ & $(0.025)$ & $0.114^{* * *}$ & $(0.026)$ \\
\hline \multirow[t]{2}{*}{ Age-at-arrival } & Mother & & & 0.002 & $(0.001)$ & 0.001 & $(0.001)$ & $0.006^{* * *}$ & $(0.002)$ & $0.007^{* * *}$ & $(0.002)$ \\
\hline & Father & & & $0.005^{* *}$ & $(0.001)$ & $0.003^{*}$ & $(0.001)$ & $0.005^{* * *}$ & $(0.001)$ & $0.006^{* * *}$ & $(0.001)$ \\
\hline \multirow[t]{6}{*}{ Mother's (highest) education at arrival } & Lower & & & & & \multicolumn{6}{|c|}{ (Reference) } \\
\hline & Vocatio & & & & & $0.183^{* * *}$ & $(0.037)$ & $0.166^{* * *}$ & $(0.037)$ & $0.164^{* * *}$ & $(0.037)$ \\
\hline & High sc & & & & & $0.195^{* * *}$ & $(0.039)$ & $0.174 * * *$ & $(0.039)$ & $0.170^{* * *}$ & $(0.039)$ \\
\hline & Short c) & & & & & 0.118 & $(0.077)$ & 0.095 & $(0.077)$ & 0.089 & $(0.077)$ \\
\hline & Mediun & cation & & & & $0.310^{* * *}$ & $(0.065)$ & $0.282^{* * *}$ & $(0.065)$ & $0.272^{* * *}$ & $(0.065)$ \\
\hline & Long C) & & & & & $0.286^{* *}$ & $(0.093)$ & $0.248^{* *}$ & $(0.093)$ & $0.243^{* *}$ & $(0.093)$ \\
\hline \multirow[t]{8}{*}{ Father's (highest) education at arrival } & Lower s & & & & & \multicolumn{6}{|c|}{ (Reference) } \\
\hline & Vocatio & & & & & 0.031 & $(0.034)$ & 0.026 & $(0.034)$ & 0.023 & $(0.034)$ \\
\hline & High sc & & & & & $0.199^{* * *}$ & $(0.045)$ & $0.192^{* * *}$ & $(0.045)$ & $0.185^{* * *}$ & $(0.045)$ \\
\hline & Short c) & & & & & 0.092 & $(0.060)$ & 0.094 & $(0.059)$ & 0.087 & $(0.059)$ \\
\hline & Mediun & cation & & & & $0.156^{*}$ & $(0.061)$ & $0.149^{*}$ & $(0.061)$ & $0.144^{*}$ & $(0.061)$ \\
\hline & Long C) & & & & & $0.291^{* * *}$ & $(0.070)$ & $0.284^{* * *}$ & $(0.070)$ & $0.279 * * *$ & $(0.069)$ \\
\hline & Older si & ne country & & & & & & $-0.172^{* * *}$ & $(0.018)$ & $-0.111^{* * *}$ & $(0.020)$ \\
\hline & Firstbor & & & & & & & & & $0.122^{* * *}$ & $(0.016)$ \\
\hline N & & \multicolumn{2}{|c|}{19251} & \multicolumn{2}{|c|}{19251} & \multicolumn{2}{|c|}{19251} & \multicolumn{2}{|c|}{19251} & \multicolumn{2}{|c|}{19251} \\
\hline $\operatorname{adj} \cdot R^{2}$ & & \multicolumn{2}{|c|}{0.135} & \multicolumn{2}{|c|}{0.137} & \multicolumn{2}{|c|}{0.144} & \multicolumn{2}{|c|}{0.148} & \multicolumn{2}{|c|}{0.151} \\
\hline
\end{tabular}


In Table 4, columns (1)-(3), we present results for the parameters of main interest. The results of the basic OLS regressions in column (1) show the effect on the exam grade in Danish of a change in years since migration conditional on partner's years since migration compared to the reference category $(0-4 \text { years })^{[21]}$ The general picture is that children whose parents have spent a longer time in the host country do better in the Danish exam. Moreover, the coefficient to medium- and long-term stay of mothers is about twice as large as for fathers. The size of the coefficients suggests that pupils with a long-term resident mother (more than 14 years) have grades that are about 0.2 standard deviations higher compared to pupils with a recently arrived mother ( $0-4$ years), while the same difference is only about half that size if we look at father's years since migration instead. ${ }^{[22]}$

\subsubsection{Sibling-fixed effects results}

While the basic OLS results above control for observable predetermined characteristics, we might still be concerned that remaining family-specific unobservables bias the results. Therefore, in this section, we use the multi-child sample to estimate a siblingfixed effects model to rid the results of bias caused by permanent family characteristics.

An issue when estimating sibling-fixed effects models is that we can only use a subsample of the original sample, i.e. children in families with at least two secondgeneration children, who graduated from form 9 in the 8-year period of 2002-09. This reduces the sample from about 20,000 to 12,000 children. Due to the non-random reduction of the sample where only children are omitted, we want to make sure that reducing the sample does not substantially change the results. A comparison of results of the main basic OLS specification (column (1), Table 4) for the multi-child sample with the full sample results suggests that, in spite of the coefficients in the siblings sample

Table 4 Effects of YSM on exam grades in Danish and Math

\begin{tabular}{|c|c|c|c|c|c|c|c|}
\hline & & \multicolumn{3}{|c|}{ Danish } & \multicolumn{3}{|c|}{ Mathematics } \\
\hline & & \multirow{2}{*}{$\frac{\text { Basic OLS }}{(1)}$} & \multicolumn{2}{|c|}{ Sibling fixed effects } & \multirow{2}{*}{$\frac{\text { Basic OLS }}{(4)}$} & \multicolumn{2}{|c|}{ Sibling fixed effects } \\
\hline & & & (2) & (3) & & (5) & (6) \\
\hline \multirow{6}{*}{$\begin{array}{l}\text { Mother: years since } \\
\text { migration }\end{array}$} & $5-9$ & $0.035(*)$ & 0.027 & & -0.023 & 0.025 & \\
\hline & & $(0.018)$ & $(0.026)$ & & $(0.020)$ & $(0.030)$ & \\
\hline & $10-13$ & $0.101^{* * *}$ & 0.059 & & 0.023 & 0.057 & \\
\hline & & $(0.025)$ & $(0.048)$ & & $(0.028)$ & $(0.056)$ & \\
\hline & $14+$ & $0.192^{* * *}$ & $0.110(*)$ & & $0.098^{* *}$ & 0.061 & \\
\hline & & $(0.029)$ & $(0.067)$ & & $(0.033)$ & $(0.077)$ & \\
\hline \multirow{6}{*}{$\begin{array}{l}\text { Father: years since } \\
\text { migration }\end{array}$} & $5-9$ & $0.041^{*}$ & & 0.024 & $0.064^{* *}$ & & -0.003 \\
\hline & & $(0.017)$ & & $(0.028)$ & $(0.020)$ & & $(0.032)$ \\
\hline & $10-13$ & $0.043\left(^{*}\right)$ & & 0.038 & $0.077^{* *}$ & & $\left.0.095^{*}\right)$ \\
\hline & & $(0.025)$ & & $(0.047)$ & $(0.028)$ & & $(0.054)$ \\
\hline & $14+$ & $0.114^{* * *}$ & & 0.031 & $0.148^{* * *}$ & & $0.142^{*}$ \\
\hline & & $(0.026)$ & & $(0.062)$ & $(0.029)$ & & $(0.072)$ \\
\hline$N$ (students) & & 19,251 & 10,646 & 10,646 & 18,935 & 10,411 & 10,411 \\
\hline$N$ (families) & & & 4,803 & 4,803 & & 4,705 & 4,705 \\
\hline $\operatorname{adj} . R^{2}$ & & 0.151 & 0.481 & 0.481 & 0.133 & 0.457 & 0.457 \\
\hline
\end{tabular}

Standard errors in parentheses. $\left.{ }^{*}\right) \mathrm{p}<.10,{ }^{*} \mathrm{p}<.05,{ }^{* *} \mathrm{p}<.01,{ }^{* * *} \mathrm{p}<.001$.

Controls included in columns (1)\&(2) include: country of origin, home country education, older siblings born in home country, age at arrival of father and mother; gender, firstborn. In columns (3) \& (4), controls include only gender and firstborn. 
being less precisely estimated due to the smaller sample size, the point estimates are similar (results available upon request). Thus, we are confident that potential differences between the sibling-fixed effects results and the previous results are not driven by differences between the multi-child sample and the full population.

Columns (3) and (4) of Table 4 show results from the sibling-fixed effects specifications. With sibling-fixed effects, we cannot enter father's and mother's years since migration in the same equation, since the difference between father's and mother's years since migration does not vary between siblings. Therefore, the results in Table 4 are obtained by estimating two sets of regressions: one including mother's YSM only, and one for father's YSM alone. The only controls included in the siblings-fixed effects specification are pupil's gender and an indicator for firstborns. Obviously, controls at the family level are omitted, since they are captured by the fixed effect.

The results for mother's YSM in Table 4 show that the point estimates are roughly half the size of the basic OLS estimates: having a long-term resident mother compared to a recent arriver increases Danish exam grades by about $0.1 \mathrm{SD}$. Yet, since standard errors have approximately doubled in size, most likely due to the smaller sample size, but also due to the within-family estimation method which tends to introduce more noise (measurement error), the sibling-fixed effects estimates are rather imprecisely estimated. Fixed effects point estimates for father's years since migration are small, also for long-term resident fathers, and not significant.

Thus, we cautiously conclude that there is evidence that the more years a mother has spent in the host country before her child is born the better exam grades in Danish does the child achieve. There is no evidence of a similar impact of YSM for the father.

The fact that sibling-fixed effects results are smaller (closer to zero) than OLS results confirms our prior that latent unobserved family-level characteristics (like lower ability) are related to having a child fewer years after migration as well as to lower exam grades. Thus, the fixed effects estimation changes the OLS results in the expected direction.

\subsection{Additional outcomes: the effect of years since migration on math grades, drop-out and no exam}

In this section, we present results on the effect of years since migration on three additional outcomes: math grades, drop-out and whether the pupil takes the exam or not.

Math Table 4, columns (4)-(6), presents results from basic OLS and sibling-fixed effects for grades in the math exam. The OLS results suggest that in particular father's years since migration are strongly associated with results in math. Pupils with a long-term resident father have 0.15 standard deviations higher math grades compared to pupils with a recently arrived father, while the same number for mother's years since migration is only $0.10 \mathrm{SD}$. Moreover, for mothers, only long-term residency is significantly associated with children's math grades, while already a short-term residency of fathers (5-9 years) is related to higher math grades.

When controlling for permanent family characteristics in the sibling-fixed effects specification, only father's YSM seems to matter for Math achievement. Having a mediumor long-term resident father increases math scores by 0.10 and $0.14 \mathrm{SD}$, respectively. 
Drop-out and no exam With the previous outcomes (exam grades), we focused on individuals who actually took part in the exit exam after form 9. However, as mentioned earlier, around $9 \%$ are not present at this exam - either because they choose not to sit the exam or because they drop out before the end of school (see Figure 5). In the following, we investigate whether YSM influences whether an individual drops out or does not take the exam.

Table 5 shows results on effects of YSM on drop-out and no exam. Drop-out and No exam are binary variables that are coded 1 if the pupil drops out. Thus, negative coefficients on YSM signify that longer residency of a parent in Denmark is decreasing dropout / no exam probabilities.

Table 5 shows results for drop-out from our two model specifications. The basic OLS results in column (1) suggest that only father's years since migration are important for the drop-out decision. Having a father who has spent 10 years or more in Denmark before the birth of the child decreases the drop-out probability by 2 percentage points (out of an average of 9\%) compared to having a newly immigrated father.

The sibling-fixed effects, which control for time-invariant observed and unobserved differences at the family level, show that long-term residency of the mother strongly decreases drop-out probabilities (6.6 percentage points). This effect size seems enormous, but must be seen within the special limited sample of families and pupils that contributes to estimating the coefficients. Average drop-out rates within this sample are much higher, since each family must have experienced drop-out by at least one of their children to be included in the sample. All in all, out of 4,251 families, only 592 families have variation in the drop-out variable. And thus, only these 592 families (1,438 students) contribute to estimating the coefficients. The drop-out rate in this subsample is $46 \%$. Thus, the effect of 6.6 percentage points found by using sibling-fixed

Table 5 Effects of YSM on drop out and no exam

\begin{tabular}{|c|c|c|c|c|c|c|c|}
\hline & & \multicolumn{3}{|c|}{ Drop out } & \multicolumn{3}{|c|}{ No exam } \\
\hline & & \multirow{2}{*}{$\frac{\text { Basic OLS }}{(1)}$} & \multicolumn{2}{|c|}{ Sibling fixed effects } & \multirow{2}{*}{$\frac{\text { Basic OLS }}{(4)}$} & \multicolumn{2}{|c|}{ Sibling fixed effects } \\
\hline & & & $(2)$ & $(3)$ & & $(5)$ & (6) \\
\hline \multirow{6}{*}{$\begin{array}{l}\text { Mother: years since } \\
\text { migration }\end{array}$} & $5-9$ & 0.001 & -0.014 & & -0.001 & -0.004 & \\
\hline & & $(0.006)$ & $(0.012)$ & & $(0.004)$ & $(0.008)$ & \\
\hline & $10-13$ & 0.001 & -0.017 & & -0.004 & 0.002 & \\
\hline & & $(0.008)$ & $(0.022)$ & & $(0.005)$ & $(0.014)$ & \\
\hline & $14+$ & -0.015 & $-0.066^{*}$ & & $-0.013^{*}$ & -0.011 & \\
\hline & & $(0.010)$ & $(0.032)$ & & $(0.006)$ & $(0.020)$ & \\
\hline \multirow{6}{*}{$\begin{array}{l}\text { Father: years since } \\
\text { migration }\end{array}$} & $5-9$ & -0.007 & & $-0.026^{*}$ & -0.003 & & -0.013 \\
\hline & & $(0.006)$ & & $(0.013)$ & $(0.004)$ & & $(0.008)$ \\
\hline & $10-13$ & $-0.019^{*}$ & & $-0.045^{*}$ & -0.003 & & $-0.031^{*}$ \\
\hline & & $(0.008)$ & & $(0.021)$ & $(0.005)$ & & $(0.014)$ \\
\hline & $14+$ & $-0.021^{*}$ & & -0.018 & $-0.010\left(^{*}\right)$ & & $-0.051^{* *}$ \\
\hline & & $(0.009)$ & & $(0.029)$ & $(0.006)$ & & $(0.018)$ \\
\hline$N$ (students) & & 17,413 & 9,316 & 9,316 & 21,154 & 12,393 & 12,393 \\
\hline$N$ (families) & & & 4,251 & 4,251 & & 5,577 & 5,577 \\
\hline adj. $R^{2}$ & & 0.015 & 0.168 & 0.168 & 0.008 & 0.065 & 0.066 \\
\hline
\end{tabular}

Standard errors in parentheses. $\left.{ }^{*}\right) \mathrm{p}<.10,{ }^{*} \mathrm{p}<.05,{ }^{* *} \mathrm{p}<.01,{ }^{* * *} \mathrm{p}<.001$.

Controls included in columns (1) \& (4) include: country of origin, home country education, older siblings born in home country, age at arrival of father and mother; gender, firstborn. In columns (2)/(3) \& (5)/(6), controls include only gender and firstborn. 
effects should be compared to an average drop-out rate in this specific sample of $46 \%$ rather than to the average drop-out rate in the sibling sample (for 2002-2009) of $8 \%$.

Interestingly, while only long-term residency (14+ years) of the mother seems to matter for drop-out compared to short term (0-4 years), medium-term stay (5-9 and in particular 10-13 years) of the father is related to lower drop-out, while long-term residency is not. The effect sizes of 2.6 and 4.5 percentage points should again be compared to the drop-out rate of $46 \%$ in the particular sample which contributes to the estimation of the coefficients.

Table 5, columns (4) - (6) present results for the No exam outcome. The basic OLS results (column (4)) suggest that long-term residency of both fathers and mothers are associated with the no exam decision.

Results from estimation with sibling-fixed effects (columns (5) and (6)) show that only father's YSM is important for No exam: having a father who has 10 or more YSM compared to recent arrivers decreases the no exam probability by 3.1-5.1 percentage points. These estimate sizes should be compared to a mean No exam rate of $43 \%$ in this particular set of students and families who contribute to the estimation. ${ }^{[23]}$

\subsection{Heterogeneity}

Now we investigate whether the estimated effects of parents' years since migration are heterogeneous across gender.

Danish by gender Table 6, left panel, presents separate results for boys and girls for exam grades in Danish. Results from the basic OLS reveal no significant gender differences. Results from sibling-fixed effects suggest that mother's $Y S M$ only matters for boys. These

Table 6 Results by gender for Danish and Math exam grades

\begin{tabular}{|c|c|c|c|c|c|c|c|c|c|}
\hline & & \multicolumn{4}{|c|}{ Danish exam } & \multicolumn{4}{|c|}{ Math exam } \\
\hline & & \multicolumn{2}{|c|}{ Basic OLS } & \multicolumn{2}{|c|}{$\begin{array}{c}\text { Sibling fixed } \\
\text { effects }^{\mathrm{a}}\end{array}$} & \multicolumn{2}{|c|}{ Basic OLS } & \multicolumn{2}{|c|}{$\begin{array}{c}\text { Sibling fixed } \\
\text { effects }^{\mathrm{a}}\end{array}$} \\
\hline & & Boys & Girls & Boys & Girls & Boys & Girls & Boys & Girls \\
\hline \multirow{6}{*}{$\begin{array}{l}\text { Mother: years since } \\
\text { migration }\end{array}$} & $5-9$ & $0.056^{*}$ & 0.017 & 0.077 & -0.049 & 0.012 & $-0.050\left(^{*}\right)$ & 0.016 & -0.008 \\
\hline & & $(0.025)$ & $(0.025)$ & $(0.049$ & $(0.046)$ & $(0.029)$ & $(0.028)$ & $(0.058)$ & $(0.053)$ \\
\hline & $10-13$ & $0.067\left(^{*}\right)$ & $0.138^{* * *}$ & $0.213^{*}$ & 0.000 & 0.048 & 0.006 & $0.195(*)$ & 0.099 \\
\hline & & $(0.035)$ & $(0.035)$ & $(0.095)$ & $(0.083)$ & $(0.041)$ & (0.039) & $(0.113)$ & $(0.095)$ \\
\hline & $14+$ & $0.201^{* * *}$ & $0.190^{* * *}$ & $0.362^{* * *}$ & 0.035 & $0.139^{* *}$ & 0.066 & -0.006 & 0.046 \\
\hline & & $(0.042)$ & $(0.041)$ & $(0.139)$ & $(0.116)$ & $(0.048)$ & $(0.045)$ & $(0.164)$ & $(0.133)$ \\
\hline \multirow{6}{*}{$\begin{array}{l}\text { Father: years since } \\
\text { migration }\end{array}$} & $5-9$ & 0.040 & $0.046\left(^{*}\right)$ & 0.008 & -0.001 & $0.053\left(^{*}\right)$ & $0.075^{* *}$ & -0.054 & 0.055 \\
\hline & & $(0.025)$ & $(0.024)$ & $(0.056)$ & $(0.049)$ & $(0.029)$ & $(0.027)$ & $(0.066)$ & $(0.056)$ \\
\hline & $10-13$ & 0.041 & 0.050 & 0.075 & -0.104 & 0.053 & $0.099^{*}$ & 0.043 & 0.084 \\
\hline & & $(0.035)$ & $(0.035)$ & $(0.094)$ & $(0.082)$ & $(0.041)$ & (0.039) & $(0.110)$ & $(0.094)$ \\
\hline & $14+$ & $0.110^{* *}$ & $0.122^{* * *}$ & 0.169 & $-0.222^{*}$ & $0.144^{* * *}$ & $0.149^{* * *}$ & 0.142 & 0.049 \\
\hline & & $(0.037)$ & $(0.036)$ & $(0.122)$ & $(0.108)$ & $(0.042)$ & $(0.041)$ & $(0.145)$ & $(0.123)$ \\
\hline$N$ (students) & & 9,361 & 9,89 & 2,796 & 3,386 & 9,237 & 9,698 & 2,744 & 3,281 \\
\hline$N$ (families) & & & & 1,334 & 1,578 & & & 1,311 & 1,531 \\
\hline $\operatorname{adj.} R^{2}$ & & 0.126 & 0.129 & 0.465 & 0.484 & 0.131 & 0.124 & 0.461 & 0.463 \\
\hline
\end{tabular}

Standard errors in parentheses. $\left(^{*}\right) p<.10,{ }^{*} p<.05,{ }^{* *} p<.01,{ }^{* * *} p<.001$.

${ }^{a}$ Effects for mother's and father's YSM are joined in one column to save space. They are estimated.

However, in separate regressions, just as in the previous tables. 
contrasting results indicate that the family-fixed components influence girls and boys differently. Family-fixed effects include factors such as marriage pattern, norms or traditions of education and gender role patterns, and one plausible interpretation of our results would be that exactly these factors influence girls and boys differently. Thus, what we see in Table 6 is that the reason why girls who grow up in families where the mother resided long time in Denmark before birth do relatively well in Danish is that these families have some time-constant characteristics that influence girls positively; for instance, these mothers are not likely to be marriage migrants. ${ }^{[24]}$ This conclusion is consistent with earlier research on education and employment of second-generation immigrants in Denmark. ${ }^{[25]}$ When it comes to boys, within-family variation suggests that boy siblings gain from their mother having stayed longer in Denmark before birth. The effect sizes are rather large: having a long-term resident mother as compared to a recent arriver increases boys' Danish exam grades by $0.36 \mathrm{SD}$. There is not much evidence that father's years since migration aid performance of boys or girls. In fact, having a long-term resident father seems to be detrimental to girls' results in Danish relative to having a recent arriver father, which could also be interpreted in line with the previous arguments regarding norms and attitudes.

Math by gender Table 6, right panel, presents separate results for boys and girls for exam grades in math. Basic OLS results suggest that in particular long-term residence in Denmark of both parents matters for boys. For girls, fathers' YSM matters at all margins, while mothers' YSM does not - mothers' YSM of 5-9 years is even marginally detrimental to girls' math scores compared to YSM of 0-4 years.

Sibling-fixed effects by gender are generally not significant. Like for Danish grades, this indicates that family-fixed effects are important for educational outcomes. In particular, we see that the positive impact of mothers on girls is driven by between-family variation, meaning that some families for example have norms in favor of supporting education while others have not. However, since the sibling-fixed effects are not precisely estimated, the differences across approaches are generally not statistically significant.

\subsection{One potential mechanism}

In section 2.1 above, we described what parents did in the period between immigration and child birth, e.g. time spent in employment and education. We investigate further along these lines by including measures of years in employment and education as controls in the main OLS regression model. ${ }^{[26]}$ The results are shown in Table 7. The first column repeats the main results for the basic OLS specification from Table 4 for comparison. Columns (2) show results with years of father's and mother's employment included as control for the Danish and Math exam, respectively. As we would expect, the coefficient estimates on YSM drop for both parents, indicating that part of the effect of staying in Denmark runs through time spent in employment. In columns (3), we include years in education instead of years in employment. This increases the importance of $Y S M$ for mothers, though hardly significantly so, while reducing the YSMestimate for fathers. Including both years in employment and in education in columns (4), generally brings the YSM estimates for mothers back to their previous levels from the main specification (columns (1)), while rendering all YSM-estimates for fathers insignificant except for long stay with respect to exam results in Math. 
Table 7 Effects of YSM on Danish and Math grades when controlling for years in employment and education (Basic OLS)

\begin{tabular}{|c|c|c|c|c|c|c|c|c|c|c|c|}
\hline & & \multicolumn{5}{|c|}{ Danish exam } & \multicolumn{5}{|c|}{ Math exam } \\
\hline & & (1) & (2) & (3) & (4) & (5) & (1) & (2) & (3) & (4) & (5) \\
\hline \multirow[t]{6}{*}{ Mother: years since migration } & $5-9$ & $0.035(*)$ & 0.012 & 0.019 & -0.003 & & -0.023 & $-0.044^{*}$ & $-0.035(*)$ & $-0.057^{* *}$ & \\
\hline & & $(0.018)$ & $(0.018)$ & $(0.018)$ & $(0.019)$ & & $(0.020)$ & $(0.021)$ & $(0.021)$ & $(0.021)$ & \\
\hline & $10-13$ & $0.101^{* * *}$ & $0.058^{*}$ & $0.121^{* * *}$ & $0.080^{* *}$ & & 0.023 & -0.016 & $0.055(*)$ & 0.012 & \\
\hline & & $(0.025)$ & $(0.027)$ & $(0.028)$ & $(0.031)$ & & $(0.028)$ & $(0.030)$ & $(0.032)$ & $(0.035)$ & \\
\hline & $14+$ & $0.192^{* * *}$ & $0.147^{* * *}$ & $0.238^{* * *}$ & $0.195^{* * *}$ & & $0.098^{* *}$ & $0.058\left(^{*}\right)$ & $0.156^{* * *}$ & $0.110^{* *}$ & \\
\hline & & $(0.029)$ & $(0.031)$ & $(0.035)$ & $(0.037)$ & & $(0.033)$ & $(0.035)$ & $(0.039)$ & $(0.042)$ & \\
\hline \multirow[t]{6}{*}{ Father: years since migration } & $5-9$ & $0.041^{*}$ & 0.029 & 0.015 & 0.002 & & $0.064^{* *}$ & $0.047^{*}$ & 0.031 & 0.014 & \\
\hline & & $(0.017)$ & $(0.018)$ & $(0.018)$ & $(0.018)$ & & $(0.020)$ & $(0.020)$ & $(0.020)$ & $(0.021)$ & \\
\hline & $10-13$ & $0.043(*)$ & 0.016 & 0.007 & -0.023 & & $0.077^{* *}$ & 0.043 & 0.050 & 0.012 & \\
\hline & & $(0.025)$ & $(0.026)$ & $(0.028)$ & $(0.030)$ & & $(0.028)$ & $(0.030)$ & $(0.032)$ & $(0.034)$ & \\
\hline & $14+$ & $0.114^{* * *}$ & $0.083^{* *}$ & $0.084^{*}$ & 0.050 & & $0.148^{* * *}$ & $0.108^{* * *}$ & $0.144^{* * *}$ & $0.100^{*}$ & \\
\hline & & $(0.026)$ & $(0.028)$ & $(0.033)$ & $(0.035)$ & & $(0.029)$ & $(0.031)$ & $(0.037)$ & $(0.040)$ & \\
\hline \multirow[t]{2}{*}{ Years of employment, mother } & & & $0.015^{* * *}$ & & $0.016^{* * *}$ & $0.019^{* * *}$ & & $0.012^{*}$ & & $0.013^{* *}$ & $0.012^{* *}$ \\
\hline & & & $(0.004)$ & & $(0.004)$ & $(0.004)$ & & $(0.005)$ & & $(0.005)$ & $(0.005)$ \\
\hline \multirow[t]{2}{*}{ Years of employment, father } & & & $0.006^{* *}$ & & $0.007^{* *}$ & $0.009^{* * *}$ & & $0.008^{* *}$ & & $0.010^{* * *}$ & $0.011^{* * *}$ \\
\hline & & & $(0.002)$ & & $(0.002)$ & $(0.002)$ & & $(0.003)$ & & $(0.003)$ & $(0.003)$ \\
\hline \multirow[t]{2}{*}{ Years of education, mother } & & & & $0.069^{* * *}$ & $0.068^{* * *}$ & $0.068^{* * *}$ & & & $0.050^{* *}$ & $0.049^{* *}$ & $0.039^{*}$ \\
\hline & & & & $(0.016)$ & $(0.016)$ & $(0.015)$ & & & $(0.018)$ & $(0.018)$ & $(0.017)$ \\
\hline \multirow[t]{2}{*}{ Years of education, father } & & & & $0.070^{* * *}$ & $0.072^{* * *}$ & $0.071^{* * *}$ & & & $0.092^{* * *}$ & $0.094^{* * *}$ & $0.094^{* * *}$ \\
\hline & & & & $(0.011)$ & $(0.011)$ & $(0.011)$ & & & $(0.012)$ & $(0.012)$ & $(0.012)$ \\
\hline$N$ (students) & & 19,251 & 19,251 & 19,251 & 19,251 & 19,251 & 18,935 & 18,935 & 18,935 & 18,935 & 18,935 \\
\hline $\operatorname{adj} . R^{2}$ & & 0.151 & 0.152 & 0.154 & 0.155 & 0.154 & 0.133 & 0.134 & 0.137 & 0.137 & 0.136 \\
\hline
\end{tabular}


The conclusion to be drawn from these results is that mothers' years of stay in Denmark promotes child outcomes, even if this time is not spend in employment or formal education, while fathers length of stay is only promoting child outcomes when spent in employment or education.

However, there are two caveats to these results. The largest part of immigrant parents in our sample originates from countries, where the education and employment of women is not commonplace. Thus, our results may be the results of negative selection of men who are not in employment/education, while staying at home is the ordinary choice for women and therefore unrelated to any negative selection.

Also, years since migration and years spent in employment/education are necessarily related and this might affect the coefficient estimates. The correlation between YSM and years in employment in our data is between 0.6-0.7 for parents, while the correlation between YSM and years in education is only about 0.3 .

\section{Conclusion}

In this paper, we employed register data for eight cohorts of second-generation immigrant pupils to estimate the impact of each parent's years since migration on secondgeneration pupils' achievement. Achievement was measured by exam grades in the school exit exams, drop-out and no exam in form 9.

Second-generation immigrants are all born in the country of destination, but they typically differ by their families' potential for integration, i.e. their parents' years since migration, which in turn might affect their own potential for integration and its derived effect on educational outcomes. Therefore, we analyzed the effect of parents' time since migration (before the child's birth) on children's educational outcomes at the end of lower secondary education.

We analyzed father's and mother's years since migration separately, since parents in many cases do not migrate to Denmark jointly (in which case their time since migration varies), and we studied asymmetries in the effects on educational achievement early in the educational career.

To identify the model, we exploited within-family variation in years since migration at childbirth, assuming that variation in parental time since migration/spacing between births of siblings is random, conditional on observed or unobserved permanent characteristics at the family level.

We find evidence of a positive impact of parents' years since migration on children's academic achievement. Our results suggest that the mother's years since migration are generally most important for grades in Danish and mainly for boys, while the father's years since migration are most important for grades in math and for drop-out and no exam. The effect of the mother's years since migration persists no matter whether she is employed or not, while the effect of the father disappears if he is not employed. This pattern of results may indicate that the years since migration of the mother matters because she better supports Danish language acquisition when she has resided in the country for many years, while the years since migration of the father matters because he better supports the importance of education for succeeding in the Danish labor market. These results emphasize the importance of our distinction between each parent's years since migration, which contrasts the approach taken in the earlier literature. 
When we split the sample by gender, the siblings approach does not have much power. We see a positive effect of mother's years since migration on grades in Danish for boys, while most other coefficients are insignificant. However, the results indicate that family-specific effects influence girls and boys differently. A plausible explanation is that family-specific effects include factors that are closely related to norms and attitudes regarding education and gender role patterns, and that this is what shows up in the results.

\section{Endnotes}

${ }^{1}$ The expression "marriage migration" denotes the practice of immigrants residing in the country of destination to get married to someone residing in their country of origin before marriage.

${ }^{2}$ See Schaafsma and Sweetman (2001) for Canada, Bleakley and Chin (2004) (2004) Leigh and Gong (2010) and Chiswick and DebBurman (2004) for the US, and Van Ours and Veenman (2006) for the Netherlands.

${ }^{3}$ Also Alba and Nee (2003) find that longer residence in the host country is associated with higher educational achievement among children without, though, interpreting this as a causal effect.

${ }^{4}$ In US research, a lack of English proficiency is often cited as the principle barrier for poor school performance among many first- and second-generation children Cosden et al. (1995; Alba et al. 2002).

${ }^{5}$ The spouse may bring children born in the home country with her, but since these children are not born in Denmark (i.e. first generation), they are not included in our study.

${ }^{6}$ E.g. 16 years mean "16 years or more" since we only know that these parents have lived in Denmark since 1972 or longer.

${ }^{7}$ This is for parents who immigrated in 1980 or later. Another measure of years in employment can be calculated also for parents arriving prior to 1980. The results are essentially unchanged.

${ }^{8}$ Virtually all fathers and mothers with missing year of arrival, have a value of YSM prior to birth of the child in question of 14 years or more. There are only 60 pupils (less than $0.5 \%$ ) for whom this is not true due to occurrence of the infrequent combination of a 15-year old pupil taking the $9^{\text {th }}$ grade exam in 2002 (the normal age is 16 years) and a parent arriving before 1973. We delete these individuals from the estimation sample.

${ }^{9}$ In preliminary analyzes, we also ran regressions for oral exam grades, but results were generally not significant.

${ }^{10}$ For $2002-06$, a specific grade is given for written math, while for 2007-09, we compute the average of the grade for mathematical skills and mathematical problem solving.

${ }^{11}$ The possible grades were $00,03,5,6,7,8,9,10,11$ and $13 ; 6$ is the lowest passing grade, and 8 represents average performance.

${ }^{12}$ The possible grades are $12 / \mathrm{A}, 10 / \mathrm{B}, 7 / \mathrm{C}, 4 / \mathrm{D}, 02 / \mathrm{E}, 00 / \mathrm{Fx},-02 / \mathrm{F}$, and the average grade of 8 on the previous grading scale is supposed to be equal to 6 on the new scale.

${ }^{13} \mathrm{~A}$ similarly remarkable drop is seen for first-generation immigrants for whom the rate drops from almost $8 \%$ to $4-5 \%$. 
${ }^{14}$ half of these have been exempted by the headmaster, and the other half consists of no-shows.

${ }^{15}$ Here, exemplified by mothers' years since migration.

${ }^{16}$ This assumption may be violated if the ability of older siblings affects birth spacing decisions.

${ }^{17}$ For example, if parents with strong concern about their children's education decide to migrate when the children are young, these children are less likely to be set back in their education.

${ }^{18}$ Also common school effects, since it is likely that siblings attend the same school.

${ }^{19}$ Since years since migration and birth order are correlated within the family, and older siblings tend to do better than their younger brothers and sisters (Black et al. 2005), we include birth order controls.

${ }^{20}$ The exact parameter estimates are not commented on because these variables account for selection, and thus the coefficients reflect the combined effect on years since migration and grades.

${ }^{21}$ Results are almost identical when we do not condition on the partner's years since migration, and when we include an indicator for arriving together, the coefficient estimate is not significantly different from zero (not reported).

${ }^{22}$ In Section 4.4, we also estimate similar models as in column (1), but without the partner's years since migration included. The results are basically unchanged.

${ }^{23} 1,054$ students in 434 families actually contribute to estimating the coefficients on No exam.

${ }^{24}$ Both Furtado (2009), Duncan and Trejo (2011) and van Ours and Veenman (2010) show that endogamous marriage is associated with worse outcomes among the children, but no studies have looked at the potential additional detrimental effect of being born into a family where one of the parents is also a marriage migrant.

${ }^{25}$ See e.g. Nielsen et al. (2009) and Nielsen et al. (2003).

${ }^{26}$ Note, that we cannot add these controls in the sibling-fixed effects specifications, since within-family variation in these variables is orthogonal to the within-family variation in YSM, which identifies the parameter of main interest.

Competing interests

The IZA Journal of Migration is committed to the IZA Guiding Principles of Research Integrity. The authors declare that they have observed these principles.

\section{Acknowledgements}

The research was conducted while Rangvid was working at AKF, Danish Institute of Governmental Research. We are grateful for comments from an anonymous referee as well as Aycan Celikaksoy, Marianne Simonsen, Lars Skipper and participants in the workshop on Immigration, integration and school achievement, Aarhus, and in the conference on Migration: Economic Change, Social Challenge, London. We appreciate funding from the Danish Council for Independent Research (\#275-07-0233). The usual disclaimer applies.

Responsible editor : Denis Fougère

\section{Author details}

${ }^{1}$ Department of Economics and Business, Aarhus University, Fuglesangs Allé 4, Aarhus V DK-8210, Denmark. ${ }^{2}$ The Danish National Centre for Social Research (SFI), Herluf Trolles Gade 11, Copenhagen K 1052, Denmark. 
Aslund O, Skans ON BA (2009) Age at migration and social integration. IFAU Working Paper 2009-21, IFAU, Sweden Black S, Devereux P, Salvanes K (2005) The More the Merrier? The Effect of Family Size and Birth Order on Children's Education. Quarterly Journal of Economics 120:669-700

Bleakley H, Chin A (2004) Language Skills and Earnings: Evidence from Childhood Immigrants. Review of Economics and Statistics 86:481-496

Bleakley H, Chin A (2008) What Holds Back the Second Generation? The Intergenerational Transmission of Language Human Capital Among Immigrants. Journal of Human Resources 43:267-298

Bleakley H, Chin A (2010) Age at Arrival, English Proficiency, and Social Assimilation Among U.S. Immigrants. American Economic Journal: Applied Economics 2:165-192

Böhlmark A (2008) Age at immigration and school performance: A siblings analysis using Swedish register data. Labour Economics 15:1366-1387

Casey T, Dustmann C (2008) Intergenerational Transmission of Language Capital and Economic Outcomes. Journal of Human Resources 43:660-687

Chiswick B, DebBurman N (2004) Educational Attainment: Analysis by Immigrant Generation. Economics of Education Review 23:361-379

Cortes KE (2006) The Effects of Age at Arrival and Enclave Schools on the Academic Performance of Immigrant Children. Economics of Education Review 25:121-132

Cosden M, Zimmer J, Reyes C, Gutierrez MR (1995) Kindergarten Practices and First Grade Achievement for Latino Spanish-speaking, Latino English-speaking and Anglo Students. Journal of School Psychology 33:123-141

Duncan B, Trejo SJ (2011) Intermarriage and the Intergenerational Transmission of Ethnic Identity and Human Capital for Mexican Americans. Journal of Labor Economics 29(2):195-227

Furtado D (2009) Cross-nativity marriages and human capital levels of children. Research in Labor Economics 29:273-296

Gonzalez A (2003) The education and wages of immigrant children: the impact of age at arrival. Economics of Education Review 22:203-212

Leigh A, Gong X (2010) Does Maternal Age Affect Children's Test Scores? Australian Economic Review 43:12-27

Nielsen HS, Rosholm M, Smith N, Husted L (2003) The School-to-Work Transition of $2^{\text {nd }}$ Generation Immigrants in Denmark. Journal of Population Economics 16:755-786

Nielsen HS, Smith N, Celikaksoy A (2009) The Effect of Marriage on Education of Immigrants: Evidence from a Policy Reform Restricting Marriage Migration. Scandinavian Journal of Economics 111:457-486

OECD (2010) PISA 2009 results. Student Performance in Reading, Mathematics and Science. OECD, Paris, What Students Know and Can Do

Schaafsma J, Sweetman A (2001) Immigrant Earnings: Age at Immigration Matters. Canadian Journal of Economics 34:1066-99

Schnepf SV (2007) Immigrants' Educational Disadvantage: An Examination across Ten Countries and Three Surveys. Journal of Population Economics 20:527-545

Van Ours JC, Veenman J (2006) Age at Immigration and Educational Attainment of Young Immigrants. Economics Letters 90:310-316

Van Ours JC, Veenman J (2010) How Interethnic Marriages Affect the Educational Attainment of Children: Evidence from a Natural Experiment. Labour Economics 17:111-117

doi:10.1186/2193-9039-1-6

Cite this article as: Nielsen and Rangvid: The impact of parents' years since migration on children's academic achievement. IZA Journal of Migration 2012 1:6.

\section{Submit your manuscript to a SpringerOpen ${ }^{\circ}$ journal and benefit from:}

- Convenient online submission

- Rigorous peer review

- Immediate publication on acceptance

- Open access: articles freely available online

- High visibility within the field

- Retaining the copyright to your article

Submit your next manuscript at $\boldsymbol{~ s p r i n g e r o p e n . c o m ~}$ 